\title{
Analysis on the Problems of College Students Cheating in Examinations from the Perspective of Game Theory
}

\author{
Haowen Feng ${ }^{1}$ and Weimin Ouyang ${ }^{1, *}$
}

\author{
${ }^{1}$ Shanghai University of Political Science and Law, Shanghai, 201701, China \\ *Corresponding author. Email: oywm@shupl.edu.cn
}

\begin{abstract}
Examinations are curial components of college education and an important means to evaluate lecture effectiveness and learning outcomes. Unfortunately, exam cheatings are not uncommon despite strict policies and procedures. Strategies to prevent exam cheating are vital for universities and education authorities to manage and foster academic integrity. In this paper, we use game theory to analyze the interactions between students and invigilators in examinations. The results show that students cheating is positively related to the expected benefits obtained by negligent invigilators, while the probability of invigilators being negligent is positively related to the consequences students face after they get caught cheating. Therefore, the solutions we propose are to increase the penalty severity for invigilators who failed to be vigilant and reduce the penalty severity for students' misconduct.
\end{abstract}

Keywords: Game theory; Nash equilibrium; College students; Cheating in the examination

\section{INTRODUCTION}

Examinations are curial components of college education. It is also an important means to evaluate lecture effectiveness and learning outcomes. Examination fairness and reasonableness are imperative to the efficacy and credibility of the examination and are therefore an important factor to evaluate the usefulness and relevance of the examination. In recent years, however, academic dishonesty, especially cheating in tertiary coursework examinations, become more prominent. We observe the growth in exam cheating is not only in the number of incidents, but also in the variety and sophistication of cheating techniques, which are trending towards group cheating and commercialization. These trend examinations jeopardize the academic integrity, impair the principle of fairness, damage students mental health, weaken the cultivation of ethics, destroy the college reputation, distort the signal function of college examination results, and seriously obstruct the role examinations play in the effective education. Despite the facts that the Ministry of Education constantly updating "Administrative Regulations for common colleges and universities students"[1], the local administrative department of education at all levels emphasizing integrity and ethics every year, and every university continuously renew their policies and implementations according to the Ministry of Education files, we see the limited sign of improvement. Cheating in the examination is still growing. How to effectively control and reduce students' cheating in exams has become crucial in university education management, and is a general concern among university educators [2, 3]. This paper attempts to use the game theory to analyse the interaction model among students, and between, students and invigilators $[4,5,6]$, and discuss the internal and external factors that leads to students cheating behaviour. On this basis, we put forward the potential solutions to help universities and education authorities to formulate effective measures to prevent cheating in examinations.

\section{GAME ANALYSIS OF CHEATING IN EXAMS BETWEEN STUDENT AND STUDENT}

In the process of examination, every student has two basic strategies: cheating and not cheating. In the same exam, a student's payoff in the exam not only depends on his own knowledge, ability, physical state, improvisation and other factors, but also depends on the influence of other students' exam strategies. This paper establishes a game model for cheating in exams between students. It is assumed that: (1) The players are student $\mathrm{A}$ and $\mathrm{B}$, in which $\mathrm{A}$ and $\mathrm{B}$ can be considered as two individual student, or $\mathrm{A}$ can be considered as a student, while B is the rest of other students; (2) Student A and B act at the same time, and they can only choose one strategy, that is, either cheating or not cheating; (3) The participants' action strategy set and its corresponding utility function are public information of each participant.

We further assume that the players understand that the examination is an important means to test their knowledge pool and enhance their skills. The false results obtained by cheating cannot reflect their actual ability. In the long run, the benefits of not cheating in the examination are higher than those of cheating in the examination. Then, the principles of the game of cheating in the examination between students are: (1) the payoff of neither cheating is 
higher than the benefit of both cheating (2) when one person cheats and the other does not, the extra payoff of cheating is much greater than that of not cheating. Under this assumption, the payoff matrix of the game is shown in Table 1.

Table 1. Payment Matrix of Cheating Game between Student and Student

\begin{tabular}{|c|c|c|c|}
\hline & \multicolumn{3}{|c|}{ Student B } \\
\cline { 2 - 4 } & & cheating & not cheating \\
\hline \multirow{2}{*}{ Student A } & cheating & 2,2 & 4,1 \\
\cline { 2 - 4 } & not cheating & 1,4 & 3,3 \\
\hline
\end{tabular}

According to the above game payoff matrix, we discuss the strategy choice of student A and student B respectively.

First, consider the strategy choice of student $\mathrm{A}$ in the game between student $\mathrm{A}$ and student $\mathrm{B}$. If student $\mathrm{B}$ choose cheating" strategy, then the profit of student A in choosing "cheating" strategy is 2, and the profit of student A in choosing "not cheating" strategy is 1 , because $2>1$, the choice of "cheating" strategy is student A's optimal reaction under Student B taking "cheating" strategy; If student B choose "not cheating" strategy, then the profit of student A in choosing "cheating" strategy is 4 , and the profit of student A in choosing "not cheating" strategy is 3, because $4>3$, the choice of "cheating" strategy is student A's optimal reaction under student B taking "not cheating" strategy. Therefore, whether the student B's strategy is "cheating" or "not cheating", the dominant strategy of student A in the game between student and student team is "cheating".

Second, consider the strategy choice of student B in the game between student $\mathrm{A}$ and student $\mathrm{B}$. If student $\mathrm{A}$ choose "cheating" strategy, then the profit of student B in choosing "cheating" strategy is 2 , and the profit of student $\mathrm{B}$ in choosing "not cheating" strategy is 1 , because $2>1$, the choice of "cheating" strategy is student B's optimal reaction under student A taking "cheating" strategy; If student A choose "not cheating" strategy, then the profit of student B in choosing "cheating" strategy is 4 , and the profit of student B in choosing "not cheating" strategy is 3, because $4>3$, the choice of "cheating" strategy is student B's optimal reaction under student A taking "not cheating" strategy. Therefore, whether the student A's strategy is "cheating" or "not cheating", the dominant strategy of student B in the game between student and student team is "cheating".

Therefore, the Nash equilibrium of the above game is (cheating, cheating), that is, both student A and student B will choose to "cheat". Even though the sum of the payoff of "cheating" is lower than the sum of the payoff of "not cheating", thus falling into the famous "Prisoner's Dilemma", that is, from the perspective of individual rationality, they have no choice but to get the benefits that are both harmful to themselves and the collective.

If neither players have long-term vision or value long-term interests that is, both players only consider their current exam results, then each of them will think that the payoff from cheating in the exam is higher than that of not cheating in the exam. Therefore, the payoff from both cheating is higher than that of not cheating in the exam. Under this assumption, the payoff matrix of the game is shown in Table 2.

Table 2. Payment Matrix of Cheating Game between Student and Student

\begin{tabular}{|l|c|c|c|}
\hline \multirow{2}{*}{} & \multicolumn{3}{|c|}{ Student B } \\
\cline { 2 - 4 } Student A & cheating & 3,3 & 4,1 \\
\cline { 2 - 4 } & not cheating & 1,4 & 2,2 \\
\hline
\end{tabular}

Applying the same analysis, (cheating, cheating) is still the Nash equilibrium of the game, that is, students A and B will choose "cheating".

The above analyses show that as long as the examination environment makes "cheating" possible, for example, there is no invigilator, or invigilators are believed to be negligent, and turn a blind eye to students' "cheating" behavior, then students will inevitably choose "cheating", because this is the best strategy and is in line with students' interests.

\section{GAME ANALYSIS OF CHEATING IN EXAMS BETWEEN STUDENT AND TEACHER}

In the examination, besides the game between student and student, there is also a game between the students and the invigilator. In the exam, the invigilator has two strategies, being attentive and not attentive. Assuming that the invigilator is attentive during the exam invigilation, then the students' cheating will be found and dealt with. If the teacher is not attentive during the exam invigilation, then the students' cheating will not be found. Now, we investigate the cheating game between students and invigilators.

We assume that: (1) the players are student and invigilator, both of them are rational and seek to maximize their own interests; (2) the student and the invigilator act at the same time and can only choose one strategy, that is, the student choose to cheat or not to cheat, while the invigilator choose to be attentive or not to be attentive; (3) The players' action strategy set and their corresponding utility function are the public information of each player; (4) if students cheat in the exam, as long as the invigilator carefully invigilates the exam, the students' cheating will be found. If the invigilator does not attentively invigilate the exam but is found by the inspector, the invigilator will be penalized. Under this assumption, the payoff matrix of the game is shown in Table 3.

Among them, L: the income gained by invigilators who do not invigilate attentively; D: the penalty imposed to the invigilator after the student's cheating behavior is found by the inspection team when the invigilator does not invigilate attentively; E: the extra payoff students get from cheating; $\mathrm{C}$ : the cost paid by invigilators to deal with cheating 
properly P: The penalty students receive when they are caught cheating.

Table 3. Payment Matrix of Cheating Game between Student and Teacher

\begin{tabular}{|c|c|c|c|}
\hline \multirow{2}{*}{ Teacher } & \multicolumn{3}{|c|}{ Student } \\
\cline { 2 - 4 } & & cheating & not cheating \\
\cline { 2 - 4 } & serious & 3,3 & 4,1 \\
\cline { 2 - 4 } & not serious & 1,4 & 2,2 \\
\hline
\end{tabular}

Usually, it is impossible for students and invigilators to consistently adopt a particular fixed strategy in the examination, otherwise, the party who adopts the fixed strategy will be easily recognized by the other party, and become disadvantaged, its rational strategy choice is generally random, that is, the expected benefits of the other party choosing different strategies are the same, thus forcing the other party to have no optimal response relative to its own. According to the mixed strategy Nash equilibrium calculation method, we calculate as follows.

First, we calculate the probability of student cheating in a mixed strategy Nash equilibrium. Assuming that the probability of student cheating is $\mathrm{m}$, then the probability of student not cheating is $1-\mathrm{m}$. Then, the expected income of the invigilator who does not attentively invigilate is: $\mathrm{m} *(-\mathrm{d})$ $+(1-\mathrm{m})^{*} \mathrm{~L}$; Expected payoff for the invigilator who does attentively invigilate is: $\mathrm{m} *(-\mathrm{c})+(1-\mathrm{m}) * 0$.

Make the two equal, we have $\mathrm{m}^{*}(-\mathrm{D})+(1-\mathrm{m}) * \mathrm{~L}=\mathrm{m}^{*}(-\mathrm{C})$ $+(1-\mathrm{m}) * 0$

By solving this equation, we can get $\mathrm{m}=\mathrm{L} /(\mathrm{L}+\mathrm{D}-\mathrm{C})$

According to the formula, we can derive the following conclusions:

Obviously, the probability of student cheating is positively related to the payoffs invigilators who do not invigilate attentively, that is, the greater the payoff invigilators who do not invigilate attentively, the higher the probability of cheating.

If the penalty for not attentive invigilation is equal to the cost of attentive invigilation, then, $\mathrm{M}=1$, that is, student will cheat, because no invigilator will be willing to attentively invigilate at this time (indifferent when student cheat and earn payoff $\mathrm{L}$ if not attentive when student don't cheat, so the optimal choice is to be not attentive). What's more, if the penalty for not attentive invigilation is less than the cost of attentive invigilation, then, $M>1$, that is, student will be more surely cheat, because not attentive will be the dominant strategy for both situations for the invigilator.

If we want to reduce the probability of cheating in exams, we should try our best to reduce the cost of dealing with cheating. On students cheating in exams, the invigilator's responsibility is to objectively record students cheating in exams, and the responsibility of the faculty authorities is to strictly implement the regulations. The faculty authorities should not find excuses to reduce or even dismiss the allegation of student's misconduct, to gain the so-called "good reputation" of protecting students and shift the, the responsibility of penalizing students to the lecturers who acted as invigilator during the exams, so that the invigilator bears the image of "hindering" the students' future.

While reduce the cost of dealing with cheating as much as possible, it is necessary to increase the penalty on negligent invigilators. This can be increasing the frequency of inspection and penalty on negligent invigilators, so that the invigilators understand that the consequence of negligence is severe, and it is in their own interest to attentively invigilate, which is also responsible for the students and ultimately contribute to higher quality of education. This will create a triple win situation among students, invigilators and school.

From the formula $\mathrm{M}=\mathrm{L} /(\mathrm{L}+\mathrm{D}-\mathrm{C})$, we see that the probability of cheating is not directly related to the penalty severity on student's misconduct. This can be unexpected, but it is reasonable. This is because the only thing students worry about cheating is being found by the invigilator. If invigilator is not attentive, cheating will be students' dominant strategy. No matter how severe the penalty is, it will not impact on students' decision to cheat.

Additionally, we calculated the probability that the invigilator is not attentive in the mixed strategy Nash equilibrium state. Assuming that the probability of invigilator not attentively invigilating is $\mathrm{n}$, then the probability of invigilator attentively invigilating is $1-n$, then the expected income of students cheating in the exam is $\mathrm{n} * \mathrm{e}+(1-\mathrm{n}) *(-\mathrm{P})$; the expected income of students not cheating in the exam is $\mathrm{n} * 0+(1-\mathrm{n}) * 0$

Make the two equal, we have $n * E+(1-n) *(-P)=n * 0+(1-$ n)*0

By solving this equation, we can get $\mathrm{n}=\mathrm{P} /(\mathrm{E}+\mathrm{P})$

According to the formula, we infer that: the probability of invigilator not attentively invigilating is negatively related to the payoff from students' cheating, and positively related to the penalty on students' cheating, that is, the higher the payoff from students' cheating, the lower the probability of teacher not attentively invigilating, the greater the penalty of students' cheating, the higher the probability of invigilator not attentively invigilating.

Therefore, in order to reduce the probability of students cheating, we should first try to reduce the payoff from students' cheating in exams. For example, we can reduce the number of questions that only requires students to purely memorize certain quotations from textbooks or reference books, and so on. In addition, we should lower the penalty severity of students who committed cheating, for example, we can reduce the chances to impose administrative penalty to students, limit the use of suspension from university, permanent exclusion and other severe consequences, mainly take the punishment measures that do not detriment the future of students, for example, voiding the exam results, retaking the course, and participating campus cleaning and or other community works.

In this way, not only can students' expected payoff fall to zero (or below) when cheating in exams, but also, they will be penalized in a way that does not hinder their future They will not feel hopeless of being expelled or revoking their degrees, which will lead to the negative mentality of abandoning themselves. Moreover, it can also alleviate the 
invigilator's concern that their allegation on student's cheating behavior may cause the students to completely lose their future, which could have negative spillover effect on their families. This will therefore lead to invigilators more willing to attentively invigilate.

\section{THE PRACTICAL DILEMMA OF THE CURRENT METHODS OF DEALING WITH CHEATING}

As college students' exam cheating is becoming more prominent, the Ministry of Education and universities are dealing with students' cheating more severely. They hope to deter students from cheating with severe consequences. However, the empirical evidence is contrary to their expectation. The reason is that the penalties for cheating are too severe, which can have huge adverse impacts on students' futures. It not only leads to the dilemma of invigilators face in their invigilation, but also leads to the dilemma educational administrator face when dealing with cheating allegations. For invigilators, what should invigilators do if they find students cheating due to attentive invigilation? If they report, cheated students will face severe consequences, which may hinder their future, many invigilators would mentally struggle on this; if not, the signal of negligent invigilation will be received by students and will induce more students to cheat in exams. In practical work, due to the concern invigilators have, most of them will tend to only stop cheating behavior but rarely report cheating when they see such misbehavior or potential of such misbehavior. The only few times they would report cheating is when the students having irritating and unregretful attitude when cheating, which annoy the invigilators and diminish their mental struggle.

For the faculty authorities, once the invigilator reports the misconduct, the authorities face a dilemma in the subsequent cheating dealings. If they stick to the rules, they could face strong resistance, not only from the alleged students and their parents, but also from other faculty authorities. It is usually the case that the education administrators and invigilators prefer to follow the rules, deal with it rigorously and act as "bad guy", while the student administrators and the college they belong request for mercy and treat them with light touch, acting as "nice guy".

If things continue in this way, the education administrators, especially the invigilators, will be reluctant to deal with students' cheating because of these stressful mental burden. In the actual invigilation work, the invigilators therefore tend to only stop cheatings, but not report them. Some would even tend to act even more passively and choose to be negligent as they don't want to go through the formal cheating dealing procedures.

It can be seen that it is the current cheating treatment policies being too strict and the consequences being too severe that leads to schools, especially invigilators, being unwilling to deal with students' exam cheatings. No matter how strict the current policies and how severe the consequences, if they cannot be implemented, their deterrent effect can hardly be exerted. The current cheating treatment policies are therefore almost useless.

\section{CONCLUSION}

The above analysis on the current cheating treatments from the perspective of game theory show that the current cheating treatments are too severe, and the consequences are too harsh. The school management department, especially lecturers acting as invigilators, are not willing to report the students' cheating behavior in the examination for fear of hindering the students' future, which leads to the failure of the current cheating treatments.

Therefore, we put forward the following suggestions to effectively reduce students' exam cheating incidents:

Reduce the consequence severity for students' misconduct: the goal is not to hinder students' future. For example, impose more penalties such as voiding test results, retaking exams, and community work, and so on, and fewer administrative penalties such as suspension from university, permanent exclusion and revocation of an award including degree; Improve invigilator's benefits and better compensate the time cost and mental burden invigilators need to deal with cheating allegations; Strengthen inspections, increase the penalties on the negligent invigilators; Strictly implement the adjusted policy

\section{REFERENCES}

[1] Ministry of Education of the People's Republic of China, Administrative Regulations for common colleges and universities students, February 4, 2017. http://www.moe.gov.cn/srcsite/A02/s5911/moe_621/20 1702/t20170216_296385.html

[2] Jianhua Li, A Study on College Students' Cheating Phenomenon and Its Governance Model from the Perspective of Game Theory, University Education, pp186-189, July 2020.

[3] Jiwei Liu , Game Analysis of College Students 'Cheating in Exams and Supervisors' Behavior, Proceedings of 2017 6th International Conference on Applied Social Science (ICASS 2017) pp13-16.

[4] Weimin Ouyang, Haowen Feng, Analysis on the Predicament of College Scientific Research Team Construction from the Perspective of Game Theory, In Proc. of 2017 2nd International Conference on Humanities and Social Science (HSS2017), Shenzhen, China, on February 24-26, 2017.

[5] Avinash K. Dixit, Barry J.Nalebuff, Thinking Strategically, China Renmin University Press, April 1, 2013.

[6] Wu Guangmou, Lv Zhouxiang, Principles and Application of Game Theory, Southeast University Press, Mar. 2009. 